\title{
A Study on Organic Modification of Damping Properties of Polyurethane Materials for Building
}

\author{
Feng Zhou ${ }^{1,2}$ Jianjun $\mathrm{Gan}^{3 *}$ Xin $\mathrm{Du}^{2}$ LigangCui $^{2}$ \\ ${ }^{1}$ Water conservancy and civil engineering infrastructure safety key Laboratory, Nanchang Institute of Technology, \\ Nanchang,China,330099 \\ ${ }^{2}$ Civil and Architectural Engineering School, Nanchang Institute of Technology, 330099 Nanchang,China \\ ${ }^{3}$ School of water conservancy and ecological engineering, Nanchang Institute of Technology, 330099
}

\begin{abstract}
The damping property of viscoelastic dampers is mainly based on the shear hysteretic behavior of viscoelastic materials, so as to reduce the dynamic response of viscoelastic materials. Therefore, the viscoelastic damping properties of viscoelastic materials greatly affect the viscoelastic dampers. At present, viscoelastic materials mainly use rubber materials, but in this thesis, the excellent properties of polyurethane elastomer materials are used to replace rubber materials and applied to viscoelastic dampers. However, pure polyurethane elastomer damping properties are related to poor performance, so it should be modified. Based on the research of inorganic filler-modified polyurethane elastomer, the research group modified the three kinds of organic chemicals with hydroxyl silicone oil, HTPB liquid rubber and epoxy resin E-51, in the low frequency region of $0.025 \mathrm{~Hz}-1.5 \mathrm{~Hz}$ through the dynamic load test machine to test the damping performance.
\end{abstract}

\section{Introduction}

The polyurethane elastomers contain microphase separation structure. The soft segment provides elastic function and the hard one has the enhancement in filling and cross-linking. Many Chinese and foreign scholars have done a lot of research on changing the damping property based on the fact that the damping property of pure polyurethane elastomer is poor.

Tan Wenli ${ }^{[1]}$ and others of Jiangnan University modified the polyacrylate adhesive by hydroxyl silicone oil and studied the effect of its mechanical properties to indicate that the physical characteristics of the adhesive can be improved by modifying it. The influence of the structure and physical properties of the modified RPUF on the hydroxy-terminated liquid rubber was studied by Hejiang Ping ${ }^{[2]}$ and others of the chemical materials institute of China Institute of Engineering Physics which ascertained that the one with lower viscosity has relatively strong impact toughness, and the one with larger viscosity and polar cyanide has high mechanical loss, even the yield strength and the absorption of the buffer energy are relatively low. Pan Guangjun ${ }^{[3]}$ and others of Qingdao University of Science and technology also got the modified PUE through the epoxy resin modified PU and tested it, which shows that the hardness, tensile strength and tearing strength of PUE are the lowest when the mass fraction of epoxy resin up to $5 \%$.

The research group reacted with hydroxyl silicone oil, HTPB liquid rubber, epoxy resin E-51, and also studied the damping and mechanical properties of the modified elastomer on the basis of researching the effects of four kinds of inorganic filler of mica powder, Zinc Oxide, silica and glass fiber on the properties of polyurethane viscoelastic dampers. Test by dynamic loading test machine under $0.025 \mathrm{~Hz} \sim 1.5 \mathrm{~Hz}$, the hysteresis curve of load displacement is obtained, and the damping performance is analyzed.

\section{Experimental section}

\subsection{Raw materials and instruments}

Polyoxypropylene glycol (PPG), industrial grade, Shandong uoso Chemical Technology Co Ltd.Toluene diisocyanate (TDI), analytically pure, Bayer, Germany. 3,3'- two chlorine -4,4'- two amino two phenyl methane (MOCA), industrial grade, Suzhou Xiangyuan special Fine Chemical Co., Ltd.Hydroxy silicone oil, industrial grade, Wuxi city full Chemical Co., Ltd.Release agent for silicone oil, industrial grade, Dongguan Eagle Industry and trade limited company. The adhesive is open 218 muruk, industrial grade, Lord chemical (Shanghai) Co. Ltd. Hydroxy terminated polybutadiene, industrial grade, Sichuan multi element Pharmaceutical Technology Co., Ltd. 50T flatbed vulcanizing machine, Hebei Zheng Shi Hydraulic Machinery Co., Ltd. Dynamic loading test machine, mold, self-made, as shown in Figure 1, 2, 3 . 

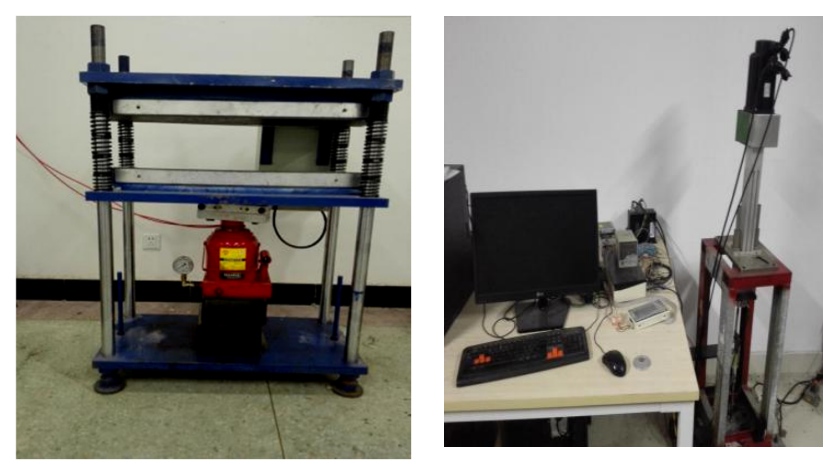

Fig $150 \mathrm{~T}$ flat vulcanizing machine

Fig 2 Dynamic load testing machine

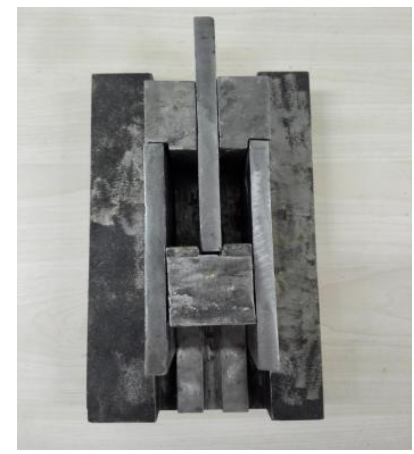

Fig 3 Mold

\subsection{Experimental method}

The specific synthesis steps are as followed. First, the calculated amount of PPG-1500 and hydroxyl silicone oil or HTPB liquid rubber should beweighed, then mix and stiritfor ultrasonic for 30 minutes, and dehydrateit for 2 hours in the electrothermal constant temperature vacuum drying box at 110 degrees, afterthat, coolit to 50 degrees in three flasks and addthe calculated TDI. Then,we should slowly heat it up to $80 \mathrm{C} \pm 5 \mathrm{C}$, and react it for $2-3 \mathrm{H}$ to get the polyurethane prepolymer in order to measure its -NCO content. Next we need to addthe calculated chain extender or epoxy resin and mix it, and stir iteven after the mixing, then to deform inject the grinding tool and curefor $30 \mathrm{~min}$ at $110 \mathrm{C}$. Last, it shouldbe pressed $4 \mathrm{H}$ on the vulcanizing machine, and cured at $110 \mathrm{C}$ for 3 hours after the demouldingto get the modified elastomer.

\subsection{Performance test}

The viscoelastic dampers made in the low frequency zone $(0.025 \mathrm{~Hz}-1.5 \mathrm{~Hz})$ are used to test the damping performance by dynamic loading test machine to get the hysteresis curves and calculate the relative damping coefficients. The design parameters of viscoelastic dampers in this experiment are shown as follows.

The equivalent damping ratio is an important index to measure the damping of viscoelastic materials. Equivalent damping ratio $=4 \pi$ times $^{[4]}$ of strain energy stored in a cycle when the energy / system dissipation is maximal.Using the related formulae of viscoelastic materials, the equivalent damping ratio of viscoelastic dampers can be calculated.

Table 1 Design parameters for viscoelastic dampers

\begin{tabular}{llccc}
\hline $\begin{array}{l}\text { Matrix } \\
\text { material }\end{array}$ & $\begin{array}{l}\text { Viscoelastic } \\
\text { area } \\
(\mathrm{mm} 2)\end{array}$ & $\begin{array}{l}\text { Viscoelasti } \\
\mathrm{c} \text { layer } \\
\text { thickness } \\
(\mathrm{mm})\end{array}$ & $\begin{array}{l}\text { steel plate } \\
\text { thickness } \\
(\mathrm{mm})\end{array}$ & $\begin{array}{l}\text { Viscoela } \\
\text { stic layer } \\
\text { number }\end{array}$ \\
\hline $\begin{array}{l}\text { polyuret } \\
\text { hane }\end{array}$ & 2500 & 15 & 10 & 2 \\
\hline
\end{tabular}

\section{Experiment and discussion}

\subsection{Unmodified polyurethane elastomer}

The hysteresis curve of polyurethane elastomers without inorganic filler is tested by dynamic loading test machine, as shown below.
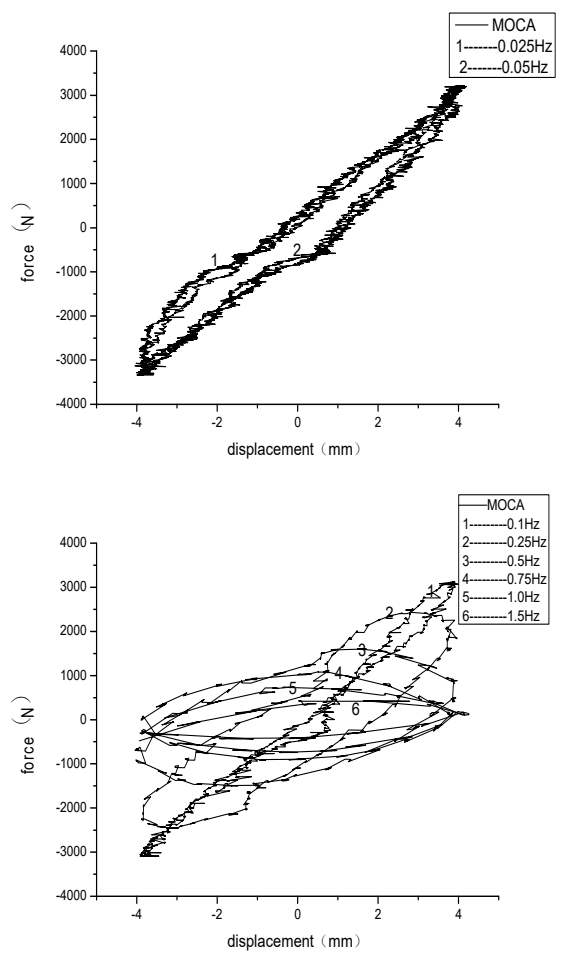

Fig 4 Hysteresis curve of unmodified elastomer

From above, through the correlation coefficient of viscoelastic material, the results are as Table 2:

Table 2 damping unmodified elastomer correlation coefficient

\begin{tabular}{llll}
\hline $\begin{array}{l}\text { Displacem } \\
\text { ent } \\
\begin{array}{c}\text { amplitude } \\
(\mathrm{mm})\end{array}\end{array}$ & $\begin{array}{l}\text { Frequency } \\
(\mathrm{Hz})\end{array}$ & $\begin{array}{l}\text { Equivalent } \\
\text { damping ratio }\end{array}$ & $\begin{array}{l}\text { Hysteresi } \\
\mathrm{s} \text { curve } \\
\text { area }(\mathrm{J})\end{array}$ \\
\hline & 0.025 & 0.09 & 7.06 \\
& 0.05 & 0.07 & 4.18 \\
& 0.1 & 0.03 & 0.73 \\
4 & 0.25 & 0.20 & 12.33 \\
& 0.5 & 0.74 & 14.65
\end{tabular}




\begin{tabular}{lll}
0.75 & 2.64 & 10.64 \\
1.0 & 1.61 & 7.65 \\
1.5 & 0.68 & 3.88 \\
\hline
\end{tabular}

Table 3 Unmodified elastomers have the corresponding maximum force at each frequency stage

\begin{tabular}{ll}
\hline frequency $(\mathrm{Hz})$ & The maximum force $(\mathrm{N})$ \\
\hline 0.025 & 3270 \\
0.05 & 3220 \\
0.1 & 3110 \\
0.25 & 2435 \\
0.5 & 1555 \\
0.75 & 995 \\
1.0 & 740 \\
1.5 & 430 \\
\hline
\end{tabular}

\subsection{Polyurethane elastomer modified by hydroxyl silicone oil}

Table 4 Hydroxyl - silicone - modified polyurethane elastomer damping correlation coefficient

\begin{tabular}{llll}
\hline $\begin{array}{l}\text { Displacement } \\
\begin{array}{c}\text { amplitude } \\
(\mathrm{mm})\end{array}\end{array}$ & $\begin{array}{l}\text { Frequency } \\
(\mathrm{Hz})\end{array}$ & $\begin{array}{l}\text { Equivalent } \\
\text { damping ratio }\end{array}$ & $\begin{array}{l}\text { Hysteresi } \\
\mathrm{s} \text { curve } \\
\text { area }(\mathrm{J})\end{array}$ \\
\hline & 0.025 & 0.11 & 1.72 \\
& 0.05 & 0.09 & 1.25 \\
4 & 0.1 & 0.05 & 0.27 \\
& 0.25 & 0.15 & 2.67 \\
& 0.5 & 0.82 & 3.43 \\
& 0.75 & 2.39 & 2.64 \\
& 1.0 & 1.98 & 1.89 \\
& 1.5 & 1.06 & 1.01 \\
\hline
\end{tabular}

Table5 Hydroxyl silicone oil modified elastomer corresponding to the maximum force at each frequency stage

\begin{tabular}{ll}
\hline frequency $(\mathrm{Hz})$ & The maximum force $(\mathrm{N})$ \\
\hline 0.025 & 459 \\
0.05 & 464 \\
0.1 & 785 \\
0.25 & 615 \\
0.5 & 378 \\
0.75 & 241 \\
1.0 & 170 \\
1.5 & 101 \\
\hline
\end{tabular}

\subsection{Polyurethane elastomer modified by liquid rubber}

Table 6 HTPB Modified Polyurethane Elastomer Damping Correlation Coefficient

\begin{tabular}{llll}
\hline $\begin{array}{l}\text { Displacement } \\
\text { amplitude } \\
(\mathrm{mm})\end{array}$ & $\begin{array}{l}\text { Frequency } \\
(\mathrm{Hz})\end{array}$ & $\begin{array}{l}\text { Equivalent } \\
\text { damping ratio }\end{array}$ & $\begin{array}{l}\text { Hysteresis } \\
\text { curve } \\
\text { area }(\mathrm{J})\end{array}$ \\
\hline & 0.025 & 0.11 & 5.47 \\
& 0.05 & 0.07 & 3.55 \\
& 0.1 & 0.09 & 2.00 \\
4 & 0.25 & 0.18 & 5.62 \\
& 0.5 & 0.75 & 8.12 \\
& 0.75 & 1.63 & 6.39 \\
& 1.0 & 2.32 & 4.80 \\
& 1.5 & 1.86 & 2.71 \\
\hline
\end{tabular}

Table 7 The HTPB modified elastomer corresponds to the maximum force at each frequency stage

\begin{tabular}{ll}
\hline frequency $(\mathrm{Hz})$ & The maximum force $(\mathrm{N})$ \\
\hline 0.025 & 1779 \\
0.05 & 1810 \\
0.1 & 1492 \\
0.25 & 1377 \\
0.5 & 909 \\
0.75 & 599 \\
1.0 & 446 \\
1.5 & 283 \\
\hline
\end{tabular}

\subsection{Epoxy resin E-51 modified polyurethane elastomer}

Table 8 Epoxy resin modified elastomer damping correlation coefficient

\begin{tabular}{llll}
\hline $\begin{array}{l}\text { Displacement } \\
\text { amplitude } \\
(\mathrm{mm})\end{array}$ & $\begin{array}{l}\text { Frequency } \\
(\mathrm{Hz})\end{array}$ & $\begin{array}{l}\text { Equivalent } \\
\text { damping ratio }\end{array}$ & $\begin{array}{l}\text { Hysteresis } \\
\text { curve region } \\
(\mathrm{J})\end{array}$ \\
\hline & 0.1 & 0.05 & 0.12 \\
4 & 0.25 & 0.18 & 6.98 \\
& 0.5 & 0.78 & 8.70 \\
& 0.75 & 2.86 & 6.52 \\
& 1.0 & 2.30 & 4.74 \\
& 1.5 & 1.92 & 2.60 \\
\hline
\end{tabular}

Table 9 The epoxy resin modified elastomer corresponds to the maximum force at each frequency stage

\begin{tabular}{ll}
\hline Frequency $(\mathrm{Hz})$ & Corresponding maximum force $(\mathrm{N})$ \\
0.1 & 1999 \\
0.25 & 1451 \\
0.5 & 934 \\
0.75 & 615 \\
1.0 & 453 \\
1.5 & 280 \\
\hline
\end{tabular}

\section{Conclusions}

1)The average equivalent damping ratio of the hydroxyl silicone elastomer was increased by $9.2 \%$, the area of the average hysteresis curve was reduced by $75.7 \%$, and the average force decreased by $73.3 \%$ in the $0.025 \mathrm{~Hz}-1.5 \mathrm{~Hz}$.

2)The average damping ratio of the HTPB modified polyurethane elastomer at $0.025 \mathrm{~Hz}-1.5 \mathrm{~Hz}$ increased by $15.8 \%$, the average hysteresis curve area decreased by $36.8 \%$, and the average force decreased by $44.8 \%$.

3 )The average equivalent damping ratio of epoxy modified polyurethane elastomers increased by $37.8 \%$ and the average hysteresis area of $0.1 \mathrm{~Hz}-1.5 \mathrm{~Hz}$ decreased by $40.6 \%$.

The viscoelastic dampers based on the polyurethane material in this paper are between rubber viscoelastic and liquid viscous dampers. Low frequency is similar to rubber viscoelastic and distributes in the first and three quadrants. High frequency is similar to liquid viscosity, distributing averagely in four quadrants. Therefore, in this paper, the low frequency is expressed by the equivalent damping coefficient and the high frequency is expressed by the energy dissipation area when measuring.

The low frequency damping performance of the polyurethane elastomer modified by organic chemicals is 
not significant, it cannot react with the liquid NBR, and the hysteresis loop of the damper is not full in the low frequency region of $0.1 \mathrm{~Hz}$.

This may be related to the smaller molecular weight of the polyurethane elastomer itself (the molecular weight is only a few thousand), and the rubber viscoelastic dampers are made of solid materials by blending which contains over 100 thousand weight of molecular. Next, we will increase the molecular weight and further study the damping capacity of high molecular weight polyurethane elastomers.

\section{Reference}

1. an Wenli, Wang Shugen, Tian Xi Zhi, Tan Wei. Preparation and Characterization of Hydroxyl Silicone Modified Polyacrylate Binder[J]. new chemical material.2009, 37 (1): 94-96.

2. He Jiangping, Liu Jing, Zhong FA Chun. Structure and Mechanical Properties of RPUF Modified by Hydroxyl Terminated Liquid Rubber [J]. polyurethane industry, 2005, (03): 1-5.

3. Pan Guangjun, Xin Haobo, Wang Xueyi, Chen Youliang, Yang Feng. Epoxy Modified Polyurethane Elastomer [J], Journal of Qingdao University of Science \& Technology (NATURAL SCIENCE EDITION), 2008, 29 (4), 334-336.

4. Clough $\mathrm{R}$ W,Penzien J.Dynamics of Structures[M].McGraw-Hill Inc,New York,1975. 